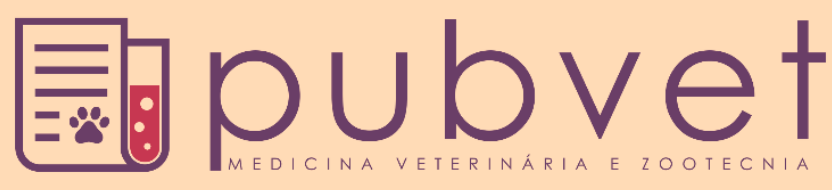

https://doi.org/10.31533/pubvet.v14n8a640.1-10

\title{
Levantamento de mielogramas com ênfase em pacientes portadores de leishmaniose visceral canina
}

\author{
Luciana Bidoia Andreoni ${ }^{*}$, Lívia Mendes Miranda ${ }^{20}$ \\ ${ }^{1}$ Graduada em Medicina Veterinária pela Universidade Anhembi Morumbi, pós-graduanda de Patologia Clínica Veterinária e Citopatologia \\ de Pequenos Animais pela ANCLIVEPA, São Paulo - SP Brasil \\ ${ }_{2}^{2}$ Mestranda em Medicina e Bem-Estar Animal pela Universidade de Santo Amaro; coordenadora do Laboratório de Patologia Clínica do \\ Hospital Veterinário Anhembi Morumbi, São Paulo - SP Brasil \\ *Autor para correspondência: medvetlu@outlook.com
}

\begin{abstract}
Resumo. Este levantamento tem como objetivo apresentar laudos e outras informações dos mielogramas realizados nos anos de 2017 e 2018 no Hospital Veterinário da Universidade Anhembi Morumbi, enfatizando animais portadores de leishmaniose visceral canina (LVC), a fim de constatar e relatar a quantidade de pacientes que apresentam a infecção por Leishmania spp. Foram analisados também os resultados de exames citológicos e sorológicos desses animais para comparação e pontuação da precisão diagnóstica e alterações laboratoriais séricas e microscópicas mais comuns causadas por esta enfermidade, respectivamente. Observaram-se alterações em hemograma e mielograma, porém animais com baixo grau de parasitismo não apresentaram Leishmania spp. em seus exames de medula óssea.
\end{abstract}

Palavras chave: leishmaniose visceral canina, medula óssea, mielograma, parasitismo

\section{Myelogram survey with emphasis on patients with canine visceral leishmaniasis}

\begin{abstract}
This survey aims to present reports and other information about myelograms performed in 2017 and 2018 at the Anhembi Morumbi University Veterinary Hospital, emphasizing animals with canine visceral leishmaniasis (CVL), to verify and report the number of patients with Leishmania spp. Infection. The results of cytological and serological exams of these animals were also analyzed for comparison and scoring of diagnostic accuracy and more common serum and microscopic laboratory changes caused by this disease, respectively. Changes in blood count and myelogram were observed, but animals with a low degree of parasitism didn't show Leishmania spp. on bone marrow exams.
\end{abstract}

Keywords: canine visceral leishmaniasis, bone marrow, myelogram, parasitism

\section{Estudio de mielogramas con énfasis en pacientes con leishmaniasis visceral canina}

Resumen. Esta investigación tiene como objetivo presentar informes y otras informaciones de los mielogramas realizados en 2017 y 2018 en el Hospital Veterinario de la Universidad Anhembi Morumbi, enfatizando animales con leishmaniasis visceral canina (LVC), con el fin de verificar e informar el número de pacientes que presentaron infección por Leishmania spp., También se analizaron los resultados de los exámenes citológicos y serológicos de estos animales para comparar y calificar la precisión diagnóstica y los cambios de laboratorio y microscópicos más comunes causados por esta enfermedad, respectivamente. Se observaron 
cambios en el recuento sanguíneo y el mielograma, pero los animales con bajo parasitismo no mostraron Leishmania spp. en sus exámenes de médula ósea.

Palabras clave: leishmaniasis visceral canina, médula ósea, mielograma, parasitismo

\section{Introdução}

Crônica e zoonótica, a leishmaniose visceral canina (LVC) é uma doença causada por protozoários do gênero Leishmania, que desenvolvem seu ciclo biológico em dois hospedeiros, sendo eles um vertebrado e um invertebrado (vetor). O hospedeiro invertebrado é um flebótomo psicodídeo (mosquitopalha), enquanto o hospedeiro vertebrado pode variar de acordo com a espécie de leishmânia (Santos \& Alessi, 2016). Os protozoários que causam a doença infectam células fagocitárias de seres humanos e animais (Momo, 2013), células estas que podem ser da derme, mucosas ou vísceras como fígado, baço e medula óssea. Comparada à leishmaniose tegumentar, a visceral é considerada mais severa (ㅍaria \& Andrade, 2012).

Objetivou-se fazer o levantamento do total de mielogramas realizados no período de janeiro de 2017 a dezembro de 2018 no Hospital Veterinário da Universidade Anhembi Morumbi, em São Paulo - SP, analisando e enfatizando as alterações causadas por Leishmania spp. nos animais infectados, observadas em seus exames de medula óssea e hemogramas. Levou-se em consideração os resultados de exames sorológicos e citológicos já realizados anteriormente nestes animais para possível comparação entre os métodos diagnósticos.

\section{Transmissão}

Sua transmissão ocorre principalmente pelo repasto sanguíneo promovido pelo flebótomo. Numa primeira fase, o flebótomo não infectado ingere macrófagos que, repletos por formas amastigotas em seu interior, liberam-nas, e estas se tornam promastigotas infecciosas não replicativas. Ao migrar para a cavidade oral do flebótomo, as promastigotas são inoculadas pela saliva na pele de um novo hospedeiro vertebrado num novo repasto sanguíneo. Uma vez inoculadas, as promastigotas são fagocitadas pelos macrófagos do novo hospedeiro, perdem seu flagelo, tornam-se amastigotas e se reproduzem por divisão binária (Santos \& Alessi, 2016). Conforme a multiplicação acontece, há a ruptura dos macrófagos infectados pela perda de sua vitalidade, liberando as formas amastigotas, que serão fagocitadas por novos macrófagos, causando disseminação hematógena e linfática para outros tecidos com abundantes células mononucleares fagocitárias, caracterizando um processo contínuo (Schimming \& Silva, 2012).

\section{Sinais, sintomas e diagnóstico}

Os sinais e sintomas clínicos de leishmaniose variam de alterações dermatológicas como dermatite esfoliativa e descamação branca prateada mais comumente em orelhas, cabeça e extremidades, dermatite ulcerativa, hiperqueratose nasodigital, alopecia, onicogrifose, a alterações sistêmicas como febre, perda de peso progressiva, caquexia, êmese, diarreia, melena, letargia, tosse, epistaxe e secreção ocular.

A anamnese e histórico do paciente são importantes para auxílio no diagnóstico, uma vez que se obtém informações sobre a região e condições ambientais do lugar de moradia, que podem reforçar suspeitas (Abbiati et al., 2019; Lima et al., 2013; Schimming \& Silva, 2012). A expansão e mudanças epidemiológicas da leishmaniose visceral acontecem por conta de vários fatores, dentre eles 0 desmatamento e as alterações no ecossistema causados pelos seres humanos (Gontijo \& Melo, 2004; Marcondes \& Rossi, 2013).

As técnicas diagnósticas têm sua importância, por exemplo, em programas de controle da leishmaniose visceral, pois tornam-se parâmetros para a escolha de quais testes realizar visando o diagnóstico positivo de animais assintomáticos e sintomáticos, principalmente quando a eutanásia é uma opção (Assis et al., 2010). Todavia, Souza et al. (2013) citam que a leishmaniose tem se espalhado cada vez mais pelo país por falta de medidas de controle eficientes. Para ilustrar este cenário, utilizaram como exemplo a eutanásia, demonstrando que é um método fortemente condenado por pesquisadores como forma de controle, uma vez que o número de casos continua crescendo. E é por isto que diagnosticar a leishmaniose precocemente é imprescindível, reforçando que é de suma importância que o médico veterinário tenha conhecimento dos principais métodos de diagnóstico para a doença. 
Os achados clínicos da LVC são muito parecidos com achados de outras enfermidades. Esta variedade de manifestações clínicas somada ao fato da maioria dos cães infectados não desenvolverem sinais da doença, dificulta o diagnóstico. Diante deste cenário, os diagnósticos laboratoriais tornam-se métodos necessários para a confirmação da enfermidade. Laboratorialmente, o diagnóstico pode ser feito por testes moleculares, sorológicos e parasitológicos, porém nenhum deles possui sensibilidade e especificidade máximas juntas.

Presente nos métodos moleculares, a reação em cadeia da polimerase (PCR) identifica e amplia as sequências de DNA do parasito, podendo chegar a $88 \%$ de sensibilidade após a infecção, apesar deste número cair posteriormente para 50\% (Barros, 2011). O PCR pode ser feito através de amostras de sangue, soro, fragmentos de pele, medula óssea, líquor, amostra conjuntival e aspirado de linfonodo (Ursine et al., 2016).

Para detectar anticorpos contra Leishmania spp., os testes sorológicos apresentam alta especificidade e sensibilidade, porém ainda assim o resultado pode ser inconclusivo para a doença, devido à outras doenças infecciosas que acabam interferindo na análise, como por exemplo a babesiose ou tripanossomíase. Dentre os testes sorológicos, estão a imunofluorescência indireta (RIFI), o ELISA (Enzyme Linked Immunosorbent Assay), a aglutinação direta, a hemaglutinação indireta, a fixação de complemento e a imunoeletroforese (Barros, 2011). A eletroforese sérica pode ser considerada um instrumento de auxílio no diagnóstico, baseado na ocorrência frequente de inversão na relação albumina/globulina (Laurenti, 2010). Ainda como alternativa, o swab de amostra conjuntival pode ser importante em animais portadores de LVC, uma vez que a conjuntiva da terceira pálpebra possui maior intensidade de parasitismo e também pelo fato de ser uma técnica não invasiva e de baixo custo (Barbosa et al., 2012).

Considerado teste de excelência para diagnóstico de LVC, o parasitológico tem $100 \%$ de especificidade, mas a sensibilidade deste depende do grau de parasitismo que o infectado apresenta. Podem ser utilizadas diferentes amostras biológicas, dentre elas esfregaços de aspirado (punção) de medula óssea, linfonodo, baço, fígado, pele e sangue para visualização direta das formas amastigotas do parasito (Gonçalves, 2018).

\section{Hematologia}

Sendo um órgão dinâmico, a medula óssea é capaz de promover o remodelamento funcional e estrutural, em resposta a sinais endócrinos, fatores nutricionais, e variações na demanda por eritrócitos (células vermelhas) e leucócitos (glóbulos brancos). Os monócitos se enquadram na classificação de leucócitos mononucleares (Weiss \& Wardrop, 2010). Considerados células intermediárias de maturação contínua, os monócitos da corrente sanguínea migram para os tecidos, desenvolvendo-se em macrófagos (Thrall et al.. 2015). Por fim, os monócitos e macrófagos são células importantes no desempenho da defesa e manutenção da homeostase (Weiss \& Wardrop, 2010). A hiperplasia de monócitos e macrófagos ocorre na medula óssea em resposta à uma variedade de infecções e agentes parasitas, tais como a Leishmania spp., organismo que pode ser visualizado no interior desses monócitos e macrófagos (Harvey, 2012) (Figura 1).

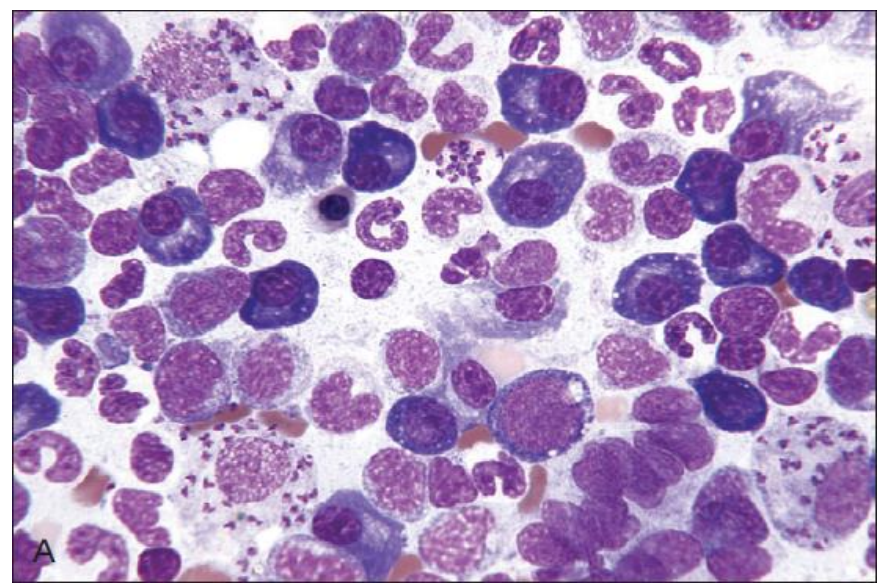

Figura 1. Três macrófagos intactos repletos de amastigotas de Leishmania dovani em aspirado de medula óssea. Fonte: Harvey (2012). 


\section{Mielograma}

A avaliação da medula óssea torna-se necessária principalmente quando há anormalidades no sangue. Este tipo de avaliação auxilia a busca e investigação de doenças que podem estar ocultas em animais que apresentam, por exemplo, febre de origem desconhecida, perda de peso e mal-estar inexplicáveis (Harvey, 2012). Utilizado para diagnosticar doenças do sistema hematopoiético como citopenias (anemia, leucopenia e trombocitopenia), o exame da medula óssea (mielograma) tornou-se importante para o estadiamento de neoplasias como linfoma e leucemias de diversas origens (Duncan \& Prasse, 1982; González \& Silva, 2008). O aspirado de medula óssea pode trazer a visualização de microrganismos como Leishmania donovani, Cytauxzoon felis, Toxoplasma gondii, Histoplasma capsulatum, Ehrlichia spp. (apesar deste último ser visto com menos frequência) e hemoparasitas como Babesia spp. e Mycoplasma spp. (Thrall, 2015).

Realizada por agulha, a citologia aspirativa de medula busca obter fragmentos para a visualização direta das células medulares, e a biópsia de medula óssea avalia a estrutura da mesma, realizada a partir de fragmentos compactos de osso, sendo um procedimento que fornece dados sobre o grau de celularidade medular, focos de infecção e quantidade de gordura no interior da medula (Müller et al., 2009). Variando de acordo com o local escolhido e a espécie do animal, as técnicas de coleta também dependem da preferência do coletor (Duncan \& Prasse, 1982; González \& Silva, 2008). Em cães e gatos, os locais de preferência são o úmero proximal, crista ilíaca, fossa trocantérica do fêmur e esterno, porém em cães de pequeno porte e gatos, os locais mais indicados são a fossa trocantérica do fêmur e úmero proximal e em cães de grande porte, úmero proximal e crista ilíaca (Cowell \& Tyler, 2009).

Os métodos e materiais variam de acordo com a literatura. Utilizam-se agulhas de 15 a 18 gauge por 1 a 2 polegadas, sendo elas Rosenthal, Illinois e Jamshidi (Cowell \& Tyler, 2009; Stockham \& Scott, 2011) e Bierman e Komiyashiki (Duncan \& Prasse, 1982; González \& Silva, 2008), placas de Petri limpas, seringas de 10 a $12 \mathrm{~mL}$, lâminas e lamínulas de microscópio limpas, materiais cirúrgicos e de forma opcional, EDTA (ácido etilenodiaminotetra-acético) líquido ou em pó e solução isotônica. Se a medula não for coletada no primeiro sítio, pode-se tentar recoletar avançando ou rotacionando a agulha, escolher outro sítio de coleta ou optar por biópsia de fragmento de medula. Se o EDTA não for utilizado, deve-se preparar o esfregaço imediatamente, em até 30 segundos após a coleta, isto é, assim que algumas gotas aparecerem na seringa, deve-se expelir o material na lâmina e preparar o esfregaço sanguíneo direto ou os de tipo squash, corandoo em seguida. Tanto na biópsia aspirativa quanto na biópsia de fragmento de medula óssea, os esfregaços já secos são corados de acordo com o protocolo do tipo Romanowsky.

No aspirado de medula óssea é analisada a celularidade e sua variação ocorre de acordo com a idade do animal. Dessa forma, o conhecimento das células normais bem como o de células neoplásicas que tem propensão de infiltração em medula é imprescindível.

Tabela 1. Observações de menor aumento (4x e 10x) de amostras citológicas de medula óssea.

\begin{tabular}{lc}
\hline Sequência & Observação \\
\hline Adequação da amostra & $\begin{array}{l}\text { Celularidade adequada, diminuída ou aumentada; morfologia celular; qualidade da } \\
\text { coloração da amostra }\end{array}$ \\
$\begin{array}{l}\text { Megacariócitos } \\
\text { morfologia e maturidade) }\end{array}$ & $\begin{array}{l}\text { (número, quantidade adequada, diminuída ou aumentada; aparência normal, displásica ou } \\
\text { Estoque de ferro }\end{array}$ \\
\hline neoplásica; maturação ordenada, desordenada ou retardada
\end{tabular}

Adaptado de Cowell \& Tyler (2009).

Tabela 2. Observação de maior aumento (40x e 100x) de amostras citológicas de medula óssea.

\begin{tabular}{|c|c|}
\hline Sequência & Observações \\
\hline $\begin{array}{l}\text { Maturação e morfologia das séries eri } \\
\text { e mieloide }\end{array}$ & $\begin{array}{l}\text { eSem alterações, displásica ou neoplásica. Maturação ordenada, retardada, desviad } \\
\text { à esquerda ou à direita, displásica ou neoplásica }\end{array}$ \\
\hline Razão M:E (mieloide:eritroide) & Sem alterações (aproximadamente 1:1), diminuída $(<1: 3)$, aumentada $(3: 1)$ \\
\hline Identificação de agentes patológicos & Leishmania spp., Ehrlichia spp., Anaplasma spp., Dirofilaria spp., Babesia spp. \\
\hline
\end{tabular}

Adaptado de Cowell \& Tyler (2009). 
A razão M:E é a relação entre células mieloides com eritroides nucleadas. Normalmente, a M:E em cães e gatos é de 0,75:1 e 2,0:1 (Cowell et al., 2009). Frequentemente é estimada, podendo ser calculada a partir dos resultados da diferenciação citológica de 500 a 1.000 células granulocíticas (mieloides) e precursores eritroides. Divide-se o número de células mieloides pelo número de células eritroides (Stockham \& Scott, 2011).

Na rotina do Hospital Veterinário da Universidade Anhembi Morumbi, o uso de placas de Petri, EDTA, solução salina e lâminas de bisturi para incisão não é comum. O local para punção preferencial é o esterno, as lâminas são feitas por squash e a coloração das amostras citológicas é feita por panótico rápido, do tipo Romanowsky.

\section{Material e métodos}

$\mathrm{O}$ estudo iniciou-se pelo levantamento de animais que passaram pelo Hospital Veterinário da Universidade Anhembi Morumbi para realização de mielograma no período de janeiro de 2017 a dezembro de 2018. Feito este levantamento, coletou-se informações dos animais, resultados de hemogramas, mielogramas e exames citológicos e sorológicos quando presentes. Os pacientes eram 62 cães de diferentes raças, idades e sexo. Os exames foram realizados no próprio ambiente do hospital citado e laudados em seu laboratório de análises clínicas. Foram realizados 62 mielogramas, 36 citologias aspirativas por agulha fina, 31 exames sorológicos por RIFI e ELISA (buscando reação para Leishmania sp. ou Ehrlichia sp.), todos dentro do próprio hospital e 2 testes moleculares (PCR) fora dele.

\section{Resultados}

Em 2017, 19 pacientes foram submetidos à coleta de medula óssea. Dos 19 pacientes, 47\% apresentaram compatibilidade com LVC enquanto 53\% apresentaram outro diagnóstico (Gráfico 1).

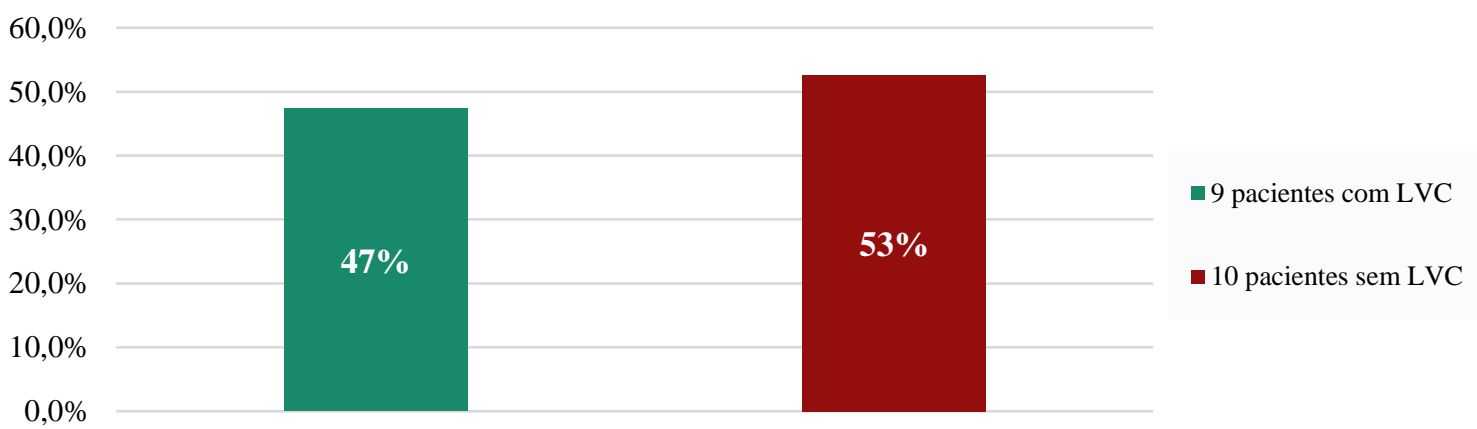

Gráfico 1. Total de diagnósticos de leishmaniose visceral canina (LVC) em 2017.

Alguns animais realizaram exames citológicos e sorológicos. Dos nove animais, 11,1\% foram diagnosticados somente por mielograma, $22,2 \%$ foram diagnosticados por mielograma e citologia, $11,1 \%$ foram diagnosticados somente por sorologia, $33,3 \%$ foram diagnosticados somente por citologia e $22,2 \%$ apresentaram citologia positiva para LVC e sorologia positiva para erliquiose canina (EC) (Gráfico 2). O diagnóstico baseou-se nos testes isolados ou na combinação entre eles.

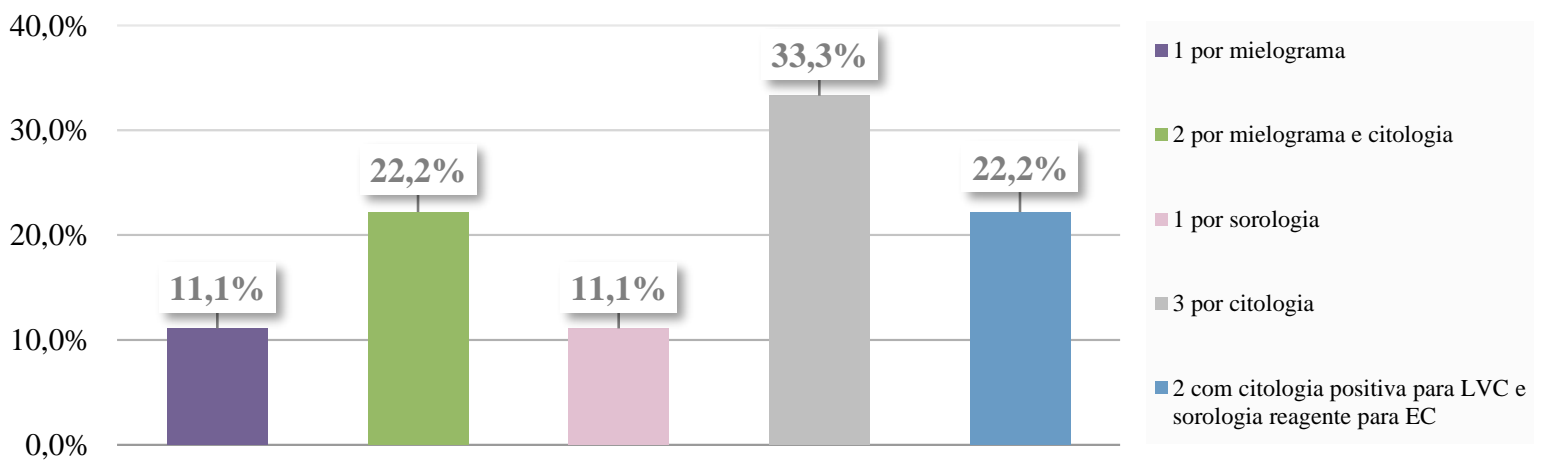

Gráfico 2. Métodos diagnósticos utilizados para confirmação da leishmaniose visceral canina (LVC) em 2017. Dois dos animais apresentaram sorologia reagente para erliquiose canina (EC). 
As amostras de medula óssea dos 19 animais foram obtidas através da punção de esterno. As por agulha fina, totalizando sete, foram obtidas através da punção de linfonodo, com exceção de uma, feita por swab de nariz e pele. As citologias por agulha fina realizadas apresentaram formas amastigotas de Leishmania sp. e em apenas três mielogramas (dos nove pacientes com LVC) realizados foram observados os parasitos. Ressalta-se que os exames citológicos foram feitos antes da punção de medula óssea. Com esta informação, conclui-se que o grau de parasitismo da LVC estava alto em três pacientes.

Dos nove animais com LVC, apenas dois apresentaram alterações em seus mielogramas (Tabela 3). $\mathrm{O}$ restante apresentou normocelularidade de todas as séries.

Tabela 3. Alterações de medula óssea de pacientes com leishmaniose visceral canina (LVC) encontradas em mielogramas realizados no ano de 2017

\begin{tabular}{llll}
\hline Animais & Resultados & & \\
\hline Paciente 1 & Hipoplasia das séries granulocítica, eritrocítica, linfo-plasmocitária e monomacrofágica. & \\
Paciente 2 & $\begin{array}{l}\text { Hipoplasia das séries granulocítica, eritrocítica, linfo-plasmocitária, monomacrofágica e } \\
\text { megacariocítica }\end{array}$ & \\
\hline
\end{tabular}

Ainda, destes nove pacientes, três apresentaram hemograma com resultados dentro da normalidade e seis apresentaram de uma a três alterações. As alterações implicaram em anemia, hiperproteinemia, trombocitopenia, leucopenia ou a combinação entre estas. Ressalta-se que nenhum deles apresentou leucocitose.

Os animais com resultado negativo para LVC apresentaram em seus mielogramas desde normocelularidade e hipoplasia a dismegacariocitopoiese e não foram observados agentes infecciosos como Ehrlichia sp.

No ano de 2018, foram realizados 43 mielogramas, onde 14 apresentaram resultados compatíveis com LVC. Dos 43 pacientes, 33\% apresentaram compatibilidade com leishmaniose visceral canina (LVC) enquanto 67\% apresentaram outro diagnóstico (Gráfico 3).

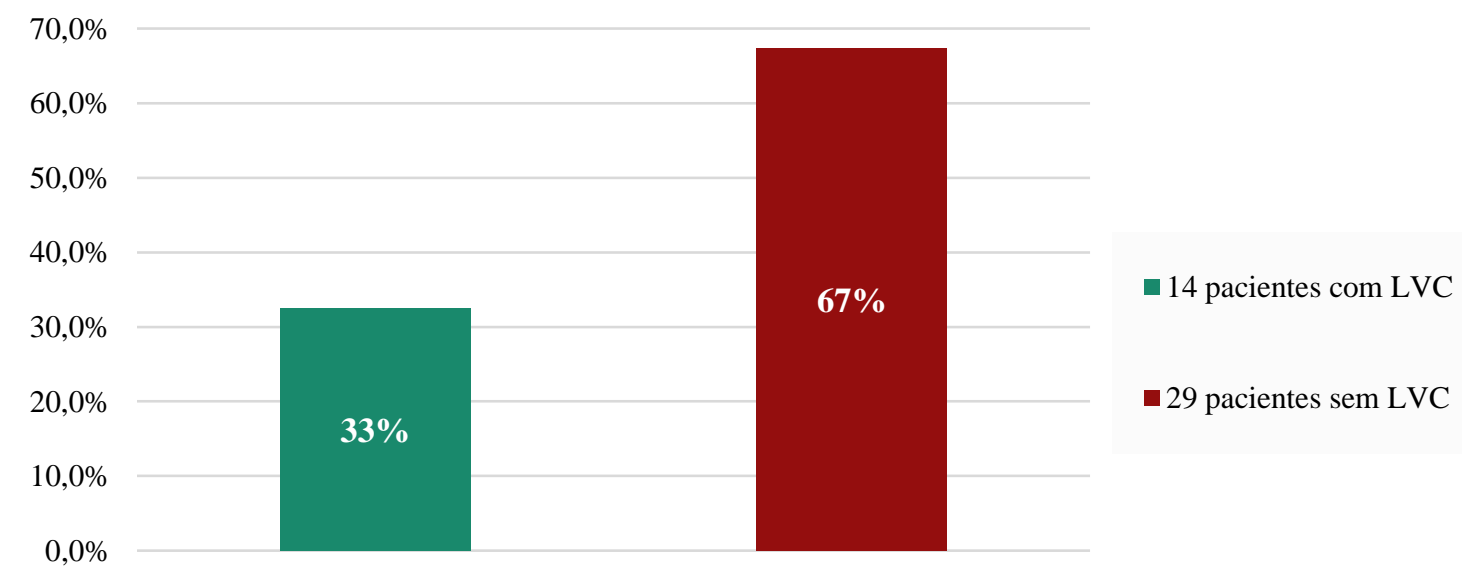

Gráfico 3. Total de diagnósticos de leishmaniose visceral canina (LVC) em 2018.

Assim como os animais de 2017, estes 14 pacientes também realizaram exames citológicos e sorológicos, tendo seu diagnóstico baseado nos testes isolados ou na combinação entre eles.

Observou-se que dos 14 animais com LVC, 14,3\% foram diagnosticados apenas por mielograma, $21,4 \%$ foram diagnosticados apenas por citologia, $7,1 \%$ foram diagnosticados por mielograma e citologia, $7,1 \%$ foram diagnosticados por citologia e sorologia, $14,3 \%$ foram diagnosticados por mielograma e sorologia, $14,3 \%$ foram diagnosticados por mielograma, citologia e sorologia, 14,3\% foram diagnosticados por PCR e 7,1\% apresentaram sorologia positiva para LVC e EC (Gráfico 4).

As amostras de medula óssea também foram obtidas por punção de esterno e as punções por agulha fina, totalizando oito, foram obtidas pela punção de linfonodo. Em sete mielogramas (dos 14 de 
pacientes com LVC) observaram-se formas amastigotas de Leishmania sp. Das oito punções de linfonodo, sete apresentaram formas amastigotas de Leishmania sp., sendo que a oitava resultou em contaminação por sangue total. Os exames citológicos também foram realizados antes da punção de medula óssea, sendo possível concluir que o grau de parasitismo da LVC estava alto em sete pacientes.

$30,0 \%$

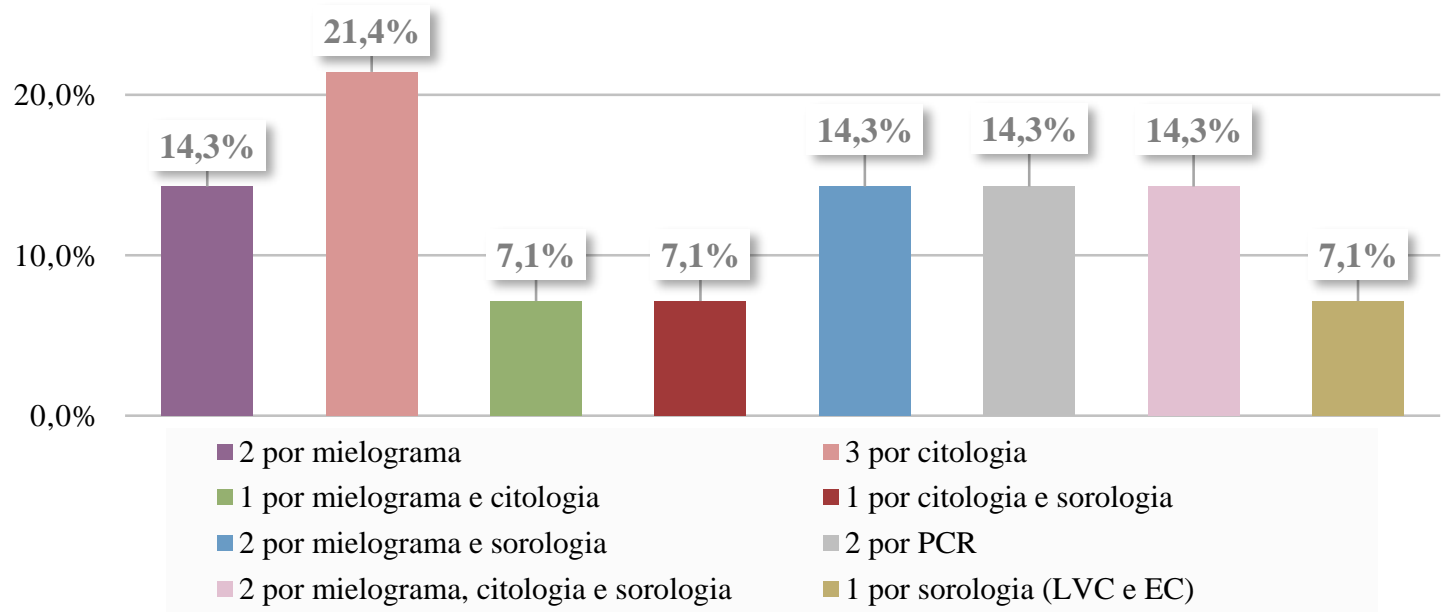

Gráfico 4. Métodos diagnósticos utilizados para confirmação da leishmaniose visceral canina (LVC) em 2018. Um dos pacientes apresentou sorologia reagente para erliquiose canina (EC).

Dos 14 animais com LVC, oito apresentaram alterações em seus mielogramas (sendo que um deles não apontou formas amastigotas de Leishmania spp.), presentes na Tabela 4 . O restante apresentou normocelularidade de todas as séries.

Tabela 4. Alterações de medula óssea de pacientes com leishmaniose visceral canina (LVC) encontradas em mielogramas realizados no ano de 2018 .

\begin{tabular}{ll}
\hline Animal & Resultados \\
\hline Paciente 1 & Hipoplasia da série eritrocítica, com diseritropoiese \\
Paciente 2 & Hipoplasia das séries granulocítica e megacariocítica \\
Paciente 3 & Hipoplasia das séries eritrocítica e megacariocítica \\
Paciente 4 & Hipoplasia da série megacariocítica \\
Paciente 5 & Hipoplasia das séries eritrocítica e megacariocítica. Hiperplasia da série granulocítica \\
Paciente 6 & Hipercelularidade da série megacariocítica. \\
Paciente 7 & Hipoplasia da série eritrocítica \\
Paciente 8 & Hipoplasia das séries eritrocítica e megacariocítica \\
\hline
\end{tabular}

Analisando seus hemogramas, constatou-se que dos 14 animais com LVC, dois apresentaram hemograma com resultados dentro da normalidade e 12 apresentaram de uma a quatro alterações. As alterações implicaram em anemia, hipoproteinemia, hiperproteinemia, trombocitopenia, leucopenia, leucocitose ou a combinação entre estas.

Os 29 animais com resultado negativo para LVC nos três testes, em seus mielogramas apresentaram desde normocelularidade, aumento ou diminuição da razão M:E, hipoplasia, hiperplasia e diseritropoiese a anemia hemolítica imunomediada, dismegacariocitopoiese, leucemia linfoide aguda e leucemia linfocítica crônica. Também não foram visualizados agentes infecciosos como Ehrlichia sp. em nenhuma amostra.

\section{Discussão}

De acordo com Medeiros et al. (2008), seu estudo experimental de perfis hematológicos em cães com leishmaniose visceral revelou que dentro do grupo de 290 cães utilizados (145 eram reagentes e 
145 eram não reagentes) os valores de hematócrito, proteína plasmática total, leucócitos e plaquetas dos animais reagentes em comparação aos não reagentes, eram significativamente inferiores, superiores e semelhantes, respectivamente.

Dependendo da fase da doença, a resposta leucocitária se altera. Em alguns animais infectados, pode haver leucocitose por neutrofilia com desvio à esquerda caso haja infecções bacterianas secundárias. A diminuição de linfócitos aparece frequentemente, ocorrendo pelo sequestro celular, promovido pelo baço e linfonodos, além de serem destruídas pelas leishmânias. Por conta dessa linfopenia, a monocitose ocorre por mecanismo compensatório (Medeiros et al., 2008). Todavia, Momo (2013) cita que animais infectados podem apresentar linfocitose, pois os linfócitos estão envolvidos diretamente na resposta imune contra a Leishmania sp. e que a observação de plasmócitos em grande quantidade é possível dependendo da severidade dos sinais clínicos da doença.

Alguns animais deste levantamento apresentaram hipoplasia nas séries granulocítica, linfoplasmocitária e monomacrofagocitária e alterações em hemograma como leucopenia e hipoproteinemia, diferentemente dos achados citados acima.

Como o parasito pode estar presente na medula óssea e em suas células, pode ocorrer aplasia medular, levando a anemia não regenerativa (Monteiro et al., 2005; Schimming \& Silva, 2012; Silva \& Winck, 2018). Cães com LVC podem apresentar alterações nas linhagens eritrocitária, leucocitária e trombocitária, levando a medula óssea a apresentar displasia ou hipoplasia megacariocítica e eritroide, emperipoleses, e distúrbios hemostáticos, que ocorrem pela disfunção plaquetária (Almeida, 2017).

Observou-se que o restante dos animais parasitados por Leishmania spp. apresentaram alterações hematológicas em seus exames como anemia, hiperproteinemia, trombocitopenia e leucocitose, além de alterações nas séries eritrocíticas e megacariocíticas da medula óssea, como hipoplasia e assincronia maturativa (diseritropoiese), resultados estes compatíveis com os citados por Medeiros et al. (2008) e Almeida (2017), com exceção da diseritropoiese.

\section{Conclusão}

A partir deste levantamento, foi possível concluir que a leishmaniose visceral canina causa alterações sistêmicas, que podem variar de acordo com a resposta imune do animal e da progressão da doença. Quando se escolhe o mielograma como teste diagnóstico para LVC, deve-se tomar cuidado com a sua sensibilidade, que não chega a 100\%, uma vez que esta é dependente do grau de parasitismo do animal, podendo fazer com que o resultado do mielograma seja negativo, como ocorreu em 14 animais portadores de LVC presentes neste estudo, mesmo com o exame citológico de linfonodos apresentando o parasita. Cabe ao médico veterinário responsável determinar qual método diagnóstico é mais apropriado de acordo com os sinais e sintomas clínicos de seu paciente.

\section{Referências bibliográficas}

Abbiati, T. C., Freitas, D. M., Alves, L. C., Freitas, B. G., Rezende, R. S., Barbosa, S. G., Jorge, A. L. T. A., Santos, S. M., \& Lopes, M. C. (2019). Leishmaniose visceral canina: Relato de caso. PUBVET, 13,1-8. DOI: https://doi.org/10.31533/pubvet.v13n4a307.1-8

Almeida, V. A. (2017). Alterações na medula óssea e distúrbios hematológicos na leishmaniose visceral canina. Instituto Gonçalo Moniz.

Assis, J., Queiroz, N. M. G. P., Silveira, R. de C. V., Nunes, C. M., Oliveira, T. M. F. S., Noronha Junior, A. C. F., Neves, M. F., Machado, R. Z., \& Buzetti, W. A. S. (2010). Estudo comparativo dos métodos diagnósticos para Leishmaniose Visceral em cães oriundos de Ilha Solteira, SP. Revista Brasileira de Parasitologia Veterinária, 19(1), 17-25. DOI: https://doi.org/10.1590/s1984$\underline{29612010000100005}$

Barbosa, V. T., Silva, M. A. G., Sousa, M. G., Gering, A. P., Santos, H. D., \& Laus, J. L. (2012). Detecção de formas amastigotas em exame parasitológico de esfregaço obtido a partir de suabe conjuntival de cães com leishmaniose visceral. Arquivo Brasileiro de Medicina Veterinária e Zootecnia, 64(6), 1465-1470. DOI: https://doi.org/10.1590/s0102-09352012000600009

Barros, R. M. (2011). Caracterização histopatológica da leishmaniose visceral canina no Distrito 
Federal. 102 f. Dissertação (Mestrado em Saúde Animal), Faculdade de Agronomia e Medicina Veterinária Universidade de Brasília, Faculdade de Agronomia e Medicina Veterinária.

Cowell, R. L., \& Tyler, R. D. (2009). Diagnostic cytology and hematology of the horse E-Book. Elsevier Health Sciences.

Duncan, J. R., \& Prasse, K. W. (1982). Patologia clínica veterinária. UFSM.

Faria, A. R., \& Andrade, H. M. (2012). Diagnóstico da Leishmaniose Visceral Canina: grandes avanços tecnológicos e baixa aplicação prática. Revista Pan-Amazônica de Saúde, 3(2), 47-57. DOI: https://doi.org/10.5123/s2176-62232012000200007

Gonçalves, L. F. C. T. (2018). Validação do diagnóstico molecular da leishmaniose visceral e da leishmaniose tegumentar na rotina diagnóstica de um laboratório de saúde pública, São Paulo, Brasil. Universidade de São Paulo. DOI: https://doi.org/10.11606/d.99.2018.tde-26042018-111529

Gontijo, C. M. F., \& Melo, M. N. (2004). Leishmaniose visceral no Brasil: quadro atual, desfios e perspectivas. Revista Brasileira de Epidemiologia, 7(3), 338-349. DOI: https://doi.org/10.1590/s1415-790x2004000300011

González, F. H. D., \& Silva, S. C. (2008). Patologia clínica veterinária: texto introdutório. Universidade Federal do Rio Grande do Sul.

Harvey, J. W. (2012). Veterinary hematology: A diagnostic guide and color atlas. In Louis, Missouri: Elsevier Saunders. Elselvier Saunders. DOI: https://doi.org/10.1111/vcp.12007

Laurenti, M. D. (2010). Patologia e patogenia das leishmanioses. Universidade de São Paulo. DOI: https://doi.org/10.11606/t.10.2010.tde-26112010-105228

Lima, C. A., Teixeira, K. R., Moreira, J. P. F. F., \& Teixeira, K. R. (2013). Diagnóstico da leishmaniose visceral canina: uma revisão. PUBVET, 7, 2565-2677. DOI: https://doi.org/10.22256/pubvet.v7n25.1641

Marcondes, M., \& Rossi, C. N. (2013). Leishmaniose visceral no Brasil. Brazilian Journal of Veterinary Research and Animal Science, 50(5), 341-352. DOI: https://doi.org/10.11606/issn.23183659.v50i5p341-352

Medeiros, C. M. de O., Melo, A. G. C., Lima, A. K. F., Silva, I. N. G. da, Oliveira, L. C. de, \& Silva, M. C. (2008). Perfil hematológico de cães com leishmaniose visceral nomunicípio de Fortaleza, Ceará. Ciência Animal, 18(1), 43-50.

Momo, C. (2013). Resposta imune na medula óssea e perfil hematológico de cães com leishmaniose visceral. 89 f. Tese (Doutorado) - Pós-graduação de Medicina Veterinária, Universidade Estadual Paulista, Jaboticabal.

Monteiro, E. M., Silva, J. C. F., Costa, R. T., Costa, D. C., Barata, R. A., Paula, E. V., Machado-Coelho, G. L. L., Rocha, M. F., Fortes-Dias, C. L., \& Dias, E. S. (2005). Leishmaniose visceral: estudo de flebotomíneos e infecção canina em Montes Claros, Minas Gerais. Revista Da Sociedade Brasileira de Medicina Tropical, 38(2), 147-152. DOI: https://doi.org/10.1590/s0037-86822005000200004

Müller, D. C. M., Pippi, N. L., Basso, P. C., Olsson, D. C., Santos Junior, E. B., \& Guerra, A. C. O. (2009). Técnicas e sítios de coleta de medula óssea em cães e gatos. Ciência Rural, 39(7), 22432251. DOI: https://doi.org/10.1590/s0103-84782009005000153

Santos, R. L., \& Alessi, A. C. (2016). Patologia veterinária. Roca.

Schimming, B. C., \& Silva, J. R. C. P. (2012). Leishmaniose visceral canina - Revisão de literatura. Revista Científica Eletrônica de Medicina Veterinária, 10(18), 1-5.

Silva, C. M. H. S., \& Winck, C. A. (2018). Leishmaniose visceral canina: revisão de literatura. Revista Da Universidade Vale Do Rio Verde, 16(1), 1-12.

Souza, Y. C. P., Carvalho, A. F. S., Carvalho, L. A. R., \& Mansur, V. F. R. (2013). Testes diagnósticos para leishmaniose visceral: atualidade e perspectivas. Revista Científica Eletrônica de Medicina Veterinária, 11(21), 1-16.

Stockham, S. L., \& Scott, M. A. (2011). Fundamentos de patologia clínica veterinária. In Guanabara Koogan (Vol. 8).

Thrall, M. A. (2015). Hematologia e Bioquímica Clínica Veterinária. In 2. ed. Editora Roca. 
Ursine, R. L., Paranaíba, L. F., Dias, J. V. L., Morais, H. A., \& Pires, H. H. R. (2016). Aspectos epidemiológicos da Leishmaniose Visceral humana e canina em municípios pertencentes à Superintendência Regional de Saúde de Diamantina, Minas Gerais, Brasil (2007-2012). Tempus Actas de Saúde Coletiva, 10(1), 179-193. DOI: https://doi.org/10.18569/tempus.v10i1.1716

Weiss, D. J., \& Wardrop, J. K. (2010). Schalm's Veterinary Hematology.

Recebido: 13 de fevereiro, 2020

Aprovado: 19 de março, 2020.

Disponível online: 27 agosto, 2020.

Licenciamento: Este artigo é publicado na modalidade Acesso Aberto sob a licença Creative Commons Atribuição 4.0 (CC-BY 4.0), a qual permite uso irrestrito, distribuição, reprodução em qualquer meio, desde que o autor e a fonte sejam devidamente creditados. 